\title{
Exposição ocupacional a material biológico: acompanhamento pós-acidente
}

\author{
Occupational exposure to biological material: post-accident monitoring
}

Exposición ocupacional a material biológico: vigilancia después de un accidente

\section{Marcelo Carneiro', Eliane Carlosso Krummenauer', Janete Aparecida Machado' \\ 'Hospital Santa Cruz, Comissão de Controle de Infecção e Epidemiologia Hospitalar. Universidade de Santa Cruz do Sul, Curso de Medicina. Santa Cruz do Sul-RS, Brasil.}

Após a interessante leitura da pesquisa "Fatores determinantes e condutas pós-acidente com material biológico entre profissionais do atendimento pré-hospitalar"(1), percebe-se a fragilidade da gestão de saúde para os profissionais da área, isto é, o descaso com o adequado cuidado para o cuidador. A metodologia empregada para o conhecimento e análise dos resultados demonstra que os profissionais acidentados percebem o risco e as possíveis consequências do ocorrido; no entanto, não modificam suas atitudes e tampouco utilizam seus direitos trabalhistas. O fato encontrado da maioria dos casos haver sido com fluidos biológicos corporais, possivelmente justifique a falta de interesse do profissional de atendimento pré-hospitalar (e até dos hospitalares), culminando em subnotificação. Em relação à falta de acompanhamento médico, é importante focar a necessidade de acompanhamento sorológico, apesar das selecionadas situações que necessitam de quimioprofilaxia.

O uso criterioso de medicamentos e imunoglobulinas poderia ser racionalizado com a cobrança do empregador / chefia imediata, ou do interesse do próprio profissional em conhecer seu perfil vacinal contra Hepatite B (agente infeccioso de maior probabilidade), bem como da coleta de amostra de sangue do paciente fonte. Em relação ao vírus HIV a utilização de antiretrovirais é formal após acidentes pérfuro-cortantes, mas com critérios de risco bem definidos, tendo pouca relevância para fluidos em pele, o que mais provavelmente tenha sido o que ocorreu com a amostra de casos do estudo das colegas. A importância deste esclarecimento é evitar, por outro enfoque, a ansiedade e fantasias geradas pela exposição com material biológico a esta equipe, tão exposta à sobrecarga de trabalho.

Conclui-se que ações de prevenção são necessárias e deverão ser periódicas para todos os indivíduos que compõem a equipe multiprofissional de saúde. A implementação e a utilização adequada de dispositivos de segurança são necessários, independentemente dos custos do investimento, permitindo um ambiente de trabalho salubre.

\section{REFERÊNCIA}

1. Paiva MHRS, Oliveira AC. Fatores determinantes e condutas pós-acidente com material biológico entre profissionais do atendimento pré-hospitalar. Rev Bras Enferm [Internet]. 2011 [citado 20 nov 2011]; 64(2):268-273.
Disponívelem:http://www.scielo.br/scielo.php?script = sci arttext\&pid $=$ S0034-71672011000200008\&lng = pt. http:// dx.doi.org/10.1590/S0034-71672011000200008. 